\title{
Intrauterine growth restriction: impact on cardiovascular development and function throughout infancy
}

\author{
Emily Cohen ${ }^{1,2}$, Flora Y. Wong ${ }^{1,3}$, Rosemary S.C. Horne ${ }^{1}$ and Stephanie R. Yiallourou ${ }^{1}$
}

Intrauterine growth restriction (IUGR) refers to the situation where a fetus does not grow according to its genetic growth potential. One of the main causes of IUGR is uteroplacental vascular insufficiency. Under these circumstances of chronic oxygen and nutrient deprivation, the growth-restricted fetus often displays typical circulatory changes, which in part represent adaptations to the suboptimal intrauterine environment. These fetal adaptations aim to preserve oxygen and nutrient supply to vital organs such as the brain, the heart, and the adrenals. These prenatal circulatory adaptations are thought to lead to an altered development of the cardiovascular system and "program" the fetus for life long cardiovascular morbidities. In this review, we discuss the alterations to cardiovascular structure, function, and control that have been observed in growth-restricted fetuses, neonates, and infants following uteroplacental vascular insufficiency. We also discuss the current knowledge on early life surveillance and interventions to prevent progression into chronic disease.

ntrauterine growth restriction (IUGR) refers to the situation where a fetus does not grow according to its genetic growth potential. The main cause of IUGR in developed countries is uteroplacental vascular insufficiency (1), which drives the fetus to redistribute its cardiac output to preserve oxygen and nutrient supply to the brain, heart, and adrenals. Although these adaptive circulatory changes are beneficial during intrauterine life, they are thought to cause dysfunctional development of the cardiovascular system and "program" the fetus for life long cardiovascular morbidities (2). This is also known as the Developmental Origins of Health and Disease hypothesis, which postulates that insults during intrauterine and early postnatal development can permanently change the body's structure, function, and metabolism and influence susceptibility to adult noncommunicable diseases (2). Despite their increased risk of cardiovascular disease, infants born growth restricted usually do not receive long-term cardiovascular follow-up. Depending on the definition used, IUGR can occur in up to $10 \%$ of pregnancies, and as cardiovascular disease is the number one cause of death worldwide (3), early identification of cardiovascular risk factors and targeted interventions in this high-risk population are of major clinical importance. In this review, we discuss the alterations of cardiovascular structure, function, and control that have been observed in infants born growth restricted and their implications for surveillance and intervention to prevent progression into chronic disease.

\section{CHALLENGES IN IDENTIFYING IUGR}

The current literature uses many different definitions of IUGR, which may explain some of the contradicting findings discussed in this review. Traditionally, and most commonly, IUGR is defined as a birth weight below the 10th percentile for gestational age on the normative population growth curve (4). This definition, however, merely describes those who are small for their gestational age (SGA) compared to the rest of the population. Individual growth potential is not taken into consideration, leading to misdiagnosis of constitutionally small fetuses and failure to identify larger fetuses, who are in fact growth restricted (4). IUGR is better described as the situation where a fetus does not grow according to its genetic growth potential (5). It remains challenging, however, to differentiate between SGA and IUGR. It is important to not only consider birth weight, but to take other markers of fetal compromise into account. It seems sensible to consider changes in growth rate of the individual fetus, rather than referencing single measurements to the general population (4). In the case of uteroplacental insufficiency, fetal compromise can further be identified by abnormalities on multivessel integrated Doppler analysis, as discussed below. Some authors therefore choose to define IUGR as SGA with Doppler abnormalities. In line with this definition, markers of fetal cardiovascular compromise have been related to severity of these Doppler changes $(6,7)$. It is important to note however, that even SGA fetuses with normal Doppler indices can present with cardiovascular abnormalities and placental pathology (8-10), further emphasizing the difficulty in correctly identifying IUGR. It is thus of great clinical importance that future research examines the relationships between different markers of fetal compromise

\footnotetext{
${ }^{1}$ The Ritchie Centre, Hudson Institute of Medical Research and Department of Paediatrics, Monash University, Melbourne, Australia; ${ }^{2}$ Department of Neonatology, Wilhelmina Children's Hospital/ University Medical Center Utrecht, Utrecht, The Netherlands; ${ }^{3}$ Monash Newborn, Monash Children's Hospital, Melbourne, Australia. Correspondence: Stephanie R. Yiallourou (stephanie.yiallourou@hudson.org.au)

Received 19 September 2015; accepted 5 December 2015; advance online publication 9 March 2016. doi:10.1038/pr.2016.24
} 


\section{Review $\mid$ Cohen et al.}

and long-term cardiovascular outcome. This will allow us to establish a uniform definition of IUGR and help us to identify fetuses at increased risk of cardiovascular disease.

\section{PRENATAL CIRCULATORY ADAPTATIONS}

In uteroplacental vascular insufficiency, characteristic hemodynamic changes can often be observed on multivessel integrated Doppler analysis. Abnormal uterine artery Doppler indices are suggestive of abnormal placentation and poor placental function (11). The sequence of the Doppler abnormalities within the fetal circulation is related to the gestational age at onset and severity of uteroplacental insufficiency (12). In early onset uteroplacental insufficiency, increased placental resistance leads to reduced end-diastolic flow in the umbilical artery. As pregnancy advances and placental resistance increases further, end-diastolic flow may become absent and eventually reversed (11). Both increasing placental resistance and vasoconstriction of fetal peripheral vascular beds, in addition to cerebral vasodilation, result in a preferential shift of the cardiac output toward the brain, which is referred to as "brainsparing" $(11,13)$. Lowered cerebral vascular resistance caused by local vasodilation results in higher end-diastolic flow in the middle cerebral artery as indicated by a lower pulsatility index of this artery on Doppler sonography (11). An increase in middle cerebral artery peak systolic velocity can subsequently be detected (14). Brain-sparing can also be identified by absence or reversal of end-diastolic flow in the aortic isthmus (15). A feature of advanced blood flow redistribution is the ability to visualize coronary blood flow on Doppler sonography, indicating maximal redistribution to the fetal heart ("heart-sparing") (11). Cardiac deterioration may occur and lead to a rise in central venous pressure, visualized by increased pulsatility or even reversibility of flow in the ductus venosus or the umbilical vein (11). Doppler abnormalities in these venous compartments are considered a very worrisome sign and are thought to represent fetal heart failure, indicating immediate delivery is required. In late-onset IUGR (beyond $30 \mathrm{wk}$ gestational age), the umbilical artery indices usually remain within normal limits (16). Doppler abnormalities are frequently limited to signs of brainsparing such as an abnormal pulsatility index of the middle cerebral artery and absent or reversed end-diastolic flow in the aortic isthmus $(15,16)$.

\section{VASCULAR AND CARDIAC REMODELING}

The detrimental intrauterine circumstances and the altered fetal hemodynamics have been shown to influence the development of the heart and the vascular tree, resulting in structural abnormalities of the myocardium (17) and vessel walls (18).

\section{Vascular Remodeling and Arterial Stiffness}

Hemodynamic changes which alter shear stress and wall tension result in arterial remodeling (19). It is therefore plausible that the altered fetal hemodynamics resulting from IUGR have a significant influence on the developing vascular tree, leading to altered vascular structure. Studies in animal models of IUGR have shown differences in vascular wall composition in growth-restricted fetuses, including significantly increased collagen content (20). Studies have also shown that vascular remodeling occurs in human IUGR and are summarized in Table 1. In human subjects, ultrasound measurements have demonstrated an increased aortic intima media thickness in growth-restricted fetuses compared to appropriately grown (appropriately grown for gestational age, AGA) controls (21). Increased intima media thickness is believed to be a marker of early atherosclerosis (22). In fact, postmortem histologic evaluation of the abdominal aorta of a preterm growth restricted stillborn revealed signs of inflammation in relation to the increased aortic intima media thickness, indicative of preatherosclerotic lesions (23). Increased aortic intima media thickness has also been reported within the first few days of life $(22,24-28)$ and even at $6(29)$ and $18 \mathrm{mo}(21,30)$ post-term age. In addition, the abdominal aorta of neonates born growth restricted was found to have an increased stiffness-index compared to AGA peers $(26,31,32)$. These observations, and especially their persistence throughout infancy, imply that the development of the vascular tree is altered in IUGR, leading to permanent changes in vascular structure and function, which may contribute to an increased risk of cardiovascular disease later in life.

\section{Cardiac Remodeling}

Most of our knowledge regarding cardiac remodeling in IUGR is derived from animal models. In these studies, the cardiomyocytes showed reduced maturation (33) and an increased rate of apoptosis (34). The cardiomyocytes also displayed disrupted arrangement and architecture, including shorter sarcomere length (34). Only two studies have investigated cardiac histology in human growth-restricted fetuses, both of which suggest that cardiac remodeling is also present in humans. Iruretagoyena et al. (17) conducted a postmortem study on nine severe growth-restricted and nine AGA fetuses. Compared with AGA subjects, the sarcomere length of growth-restricted fetuses was significantly shorter. As shorter sarcomeres consume less energy when contracting over a smaller distance, the authors proposed that this might be an adaptive mechanism to chronic oxygen and nutrient deprivation. However, shorter sarcomere length compromises contractility, which can lead to systolic dysfunction. A similar study, conducted by Takahashi et al., (35) showed that growth-restricted fetuses displayed thinner cardiomyocytes, indicating hypoplasia of the myocardial fibers, a slight maturational delay of the cardiomyocytes and reduced glycogen storage.

\section{CARDIAC MORPHOLOGY}

Cardiac remodeling and the altered fetal hemodynamics also influence cardiac morphology (Table 2). In IUGR, the heart experiences an increased afterload, which is initially caused by increased placental resistance and is sustained by peripheral vasoconstriction and vascular remodeling. As a result, some infants may develop cardiac hypertrophy, as demonstrated by an increased interventricular septal thickness compared to AGA controls (10,36-38). However, it is not just hypertrophy 


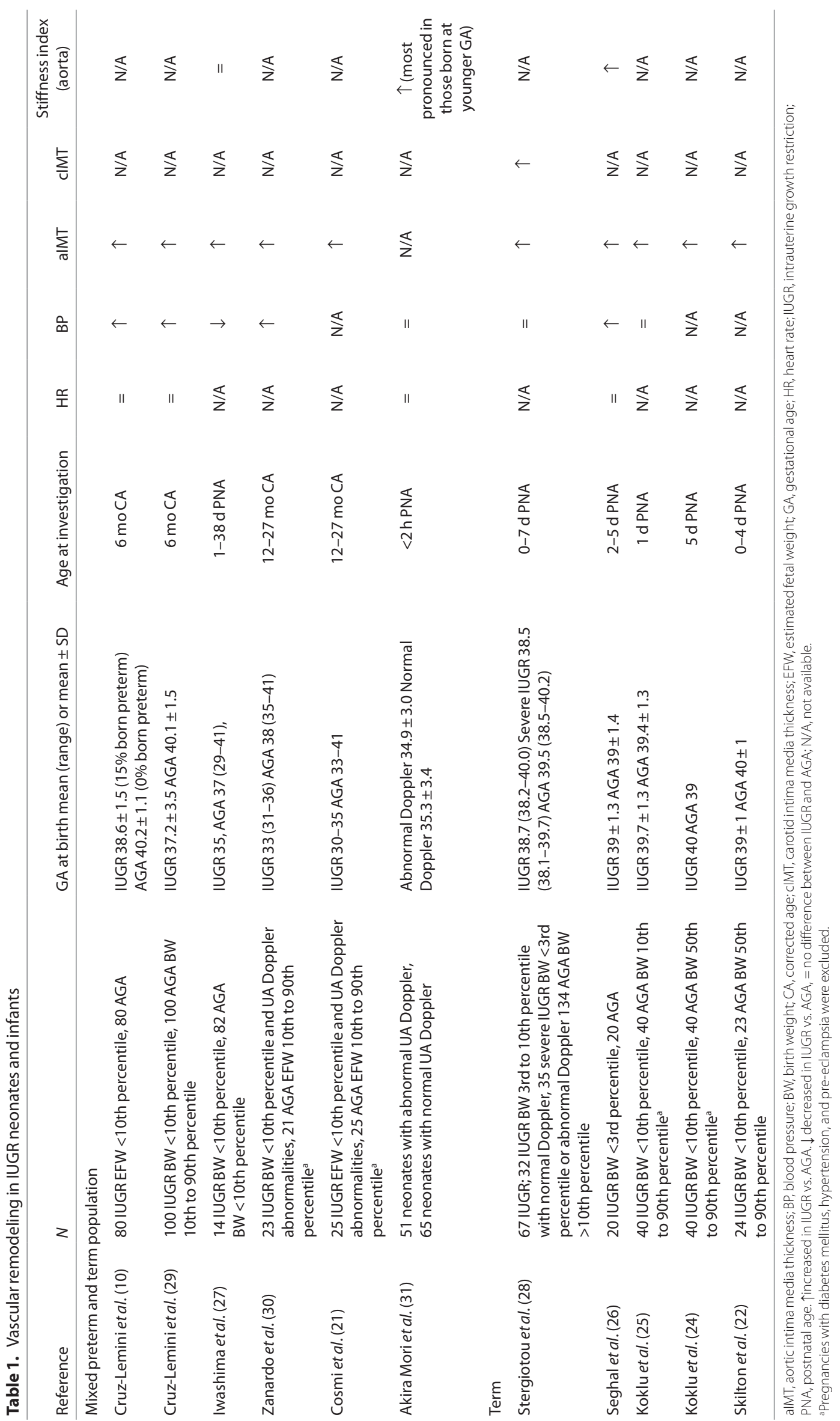


Review | Cohen et al.

\begin{tabular}{|c|c|c|c|c|c|c|c|c|c|c|c|c|c|}
\hline 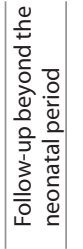 & $\frac{\mathbb{L}}{z}$ & 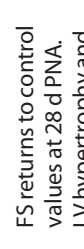 & & $\frac{\mathbb{z}}{z}$ & $\frac{\pi}{z}$ & 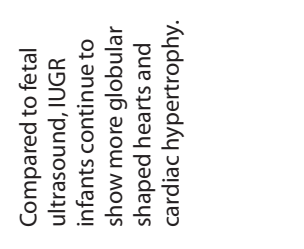 & $\stackrel{s}{z}$ & 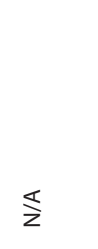 & $\stackrel{s}{z}$ & $\frac{\pi}{z}$ & 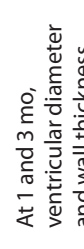 & 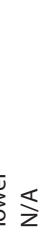 & \\
\hline$\stackrel{\stackrel{t}{\geq}}{\geq}$ & $\frac{1}{z}$ & $\stackrel{\Sigma}{z}$ & $\frac{\mathbb{z}}{z}$ & $\frac{\mathbb{z}}{z}$ & $\frac{\mathbb{z}}{z}$ & $\rightarrow$ & $\leftarrow$ & $\leftarrow$ & $\stackrel{\mathbb{s}}{z}$ & $\stackrel{\mathbb{1}}{z}$ & $\frac{s}{z}$ & $\leftarrow$ & $\frac{\pi}{2}$ \\
\hline 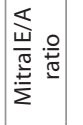 & $\frac{s}{z}$ & $\stackrel{s}{z}$ & $\stackrel{\mathbb{z}}{z}$ & $\stackrel{s}{z}$ & $\rightarrow$ & 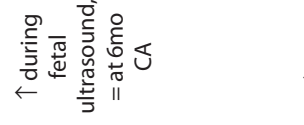 & 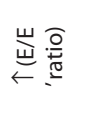 & $"$ & $\stackrel{s}{z}$ & $\stackrel{s}{z}$ & $"$ & $\leftarrow$ & $\leftarrow$ \\
\hline 出 & $\stackrel{s}{z}$ & 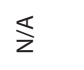 & " & $\frac{\mathbb{z}}{z}$ & $\stackrel{s}{z}$ & $\|$ & $\stackrel{s}{z}$ & $"$ & $\frac{\pi}{z}$ & $"$ & $"$ & $\$$ & $"$ \\
\hline 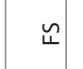 & $\stackrel{\Sigma}{z}$ & $\leftarrow$ & $"$ & $\stackrel{s}{z}$ & $\stackrel{s}{z}$ & $\stackrel{s}{z}$ & $\stackrel{\varsigma}{z}$ & $॥$ & $\stackrel{s}{z}$ & $"$ & $"$ & $\rightarrow$ & $"$ \\
\hline$\overline{\bar{a}}$ & $\stackrel{s}{z}$ & $\stackrel{s}{z}$ & $\stackrel{s}{z}$ & $\stackrel{s}{z}$ & $\stackrel{s}{z}$ & 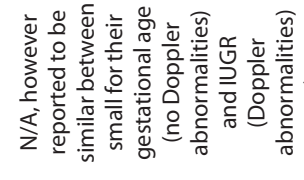 & & $\leftarrow$ & 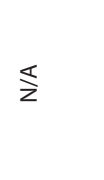 & $\stackrel{s}{z}$ & 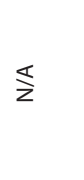 & $\stackrel{\mathbb{z}}{z}$ & $\leftarrow$ \\
\hline 8 & $\frac{\pi}{z}$ & $"$ & $\underset{0}{c}$ & & $\stackrel{s}{z}$ & $"$ & $\stackrel{s}{z}$ & 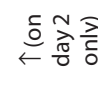 & 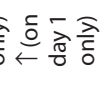 & $\stackrel{s}{z}$ & $\frac{\mathbb{s}}{z}$ & $\rightarrow$ & $\underset{\stackrel{\Xi}{\rightleftarrows}}{\rightleftarrows}$ \\
\hline$\vec{n}$ & $\frac{\pi}{z}$ & $\frac{\mathbb{s}}{z}$ & 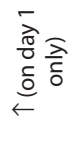 & $\rightarrow$ & 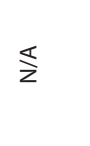 & 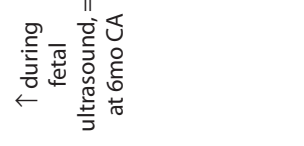 & $\stackrel{s}{z}$ & $\begin{array}{l}\stackrel{c}{0} \sqrt{n} \\
\stackrel{\vec{\pi}}{\rightleftarrows}\end{array}$ & $"$ & $\frac{\pi}{z}$ & $\frac{\mathbb{s}}{z}$ & $\rightarrow$ & 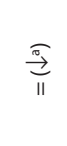 \\
\hline$\infty$ & " & $\stackrel{\mathbb{s}}{z}$ & " & $"$ & $\stackrel{s}{z}$ & $\leftarrow$ & $\stackrel{\Sigma}{z}$ & 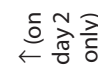 & 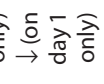 & $\frac{\pi}{z}$ & " & $\leftarrow$ & $"$ \\
\hline 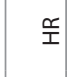 & $"$ & $"$ & $"$ & $\leftarrow$ & $"$ & " & $\leftarrow$ & $\leftarrow$ & " & $\stackrel{s}{z}$ & $\|$ & $\|$ & $\leftarrow$ \\
\hline 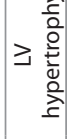 & $i$ & + & + & $\frac{\pi}{z}$ & $\frac{s}{z}$ & + & + & i & $\frac{\pi}{z}$ & $i$ & $i$ & $\stackrel{\leqslant}{z}$ & i \\
\hline 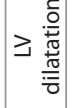 & i & + & + & 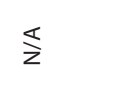 & $\frac{\mathbb{Z}}{z}$ & + & + & $i$ & $\stackrel{\alpha}{z}$ & i & i & $\stackrel{\circ}{+}$ & + \\
\hline 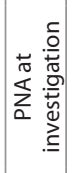 & $\stackrel{0}{\sim}$ & 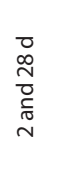 & 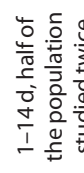 & 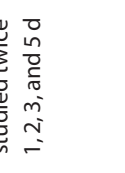 & 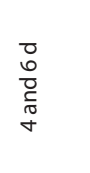 & 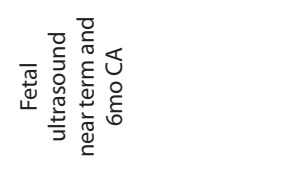 & $\begin{array}{l}\text { D } \\
\text { in } \\
\text { o } \\
\text { c } \\
\text { N }\end{array}$ & 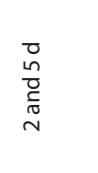 & 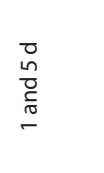 & 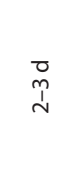 & 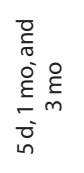 & 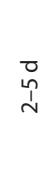 & 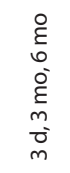 \\
\hline 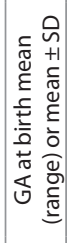 & 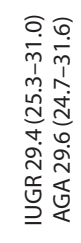 & 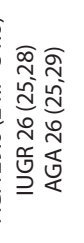 & 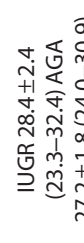 & 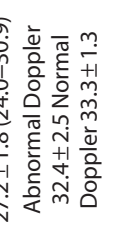 & 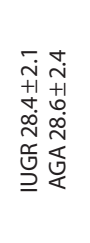 & 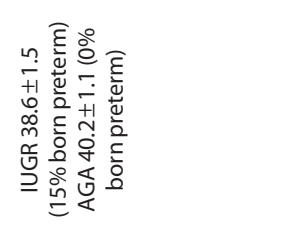 & 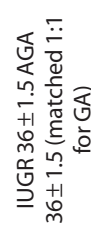 & 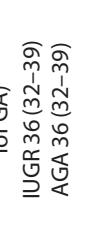 & 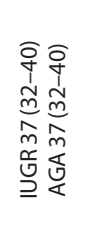 & 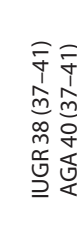 & 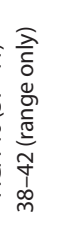 & & 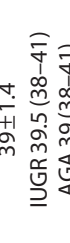 \\
\hline$z$ & 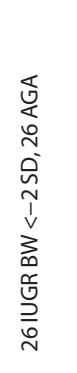 & 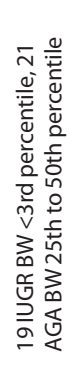 & 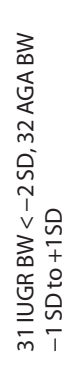 & 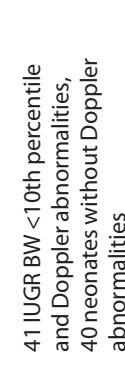 & 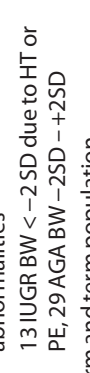 & 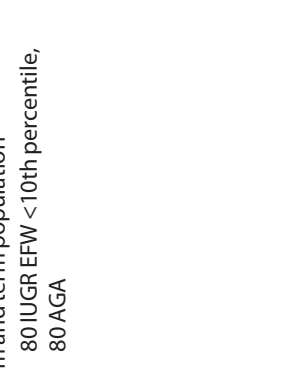 & 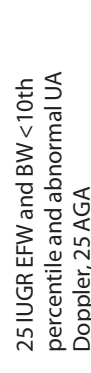 & 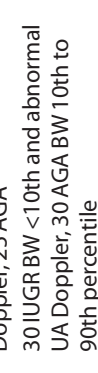 & 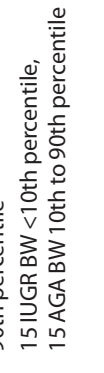 & 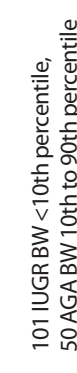 & 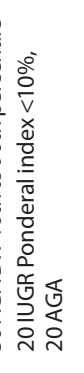 & & 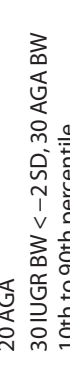 \\
\hline 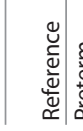 & $=\frac{\bar{d}}{0.0}$ & 竞 & 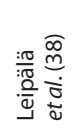 & 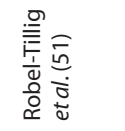 & 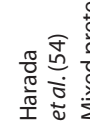 & 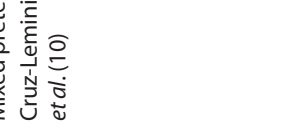 & 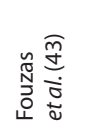 & 总 & 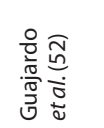 & 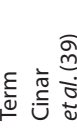 & 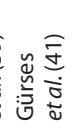 & & \\
\hline
\end{tabular}


that has been reported. The ratio of the left ventricular wall thickness to diastolic diameter ("relative wall thickness") has been found to be decreased in infants born growth restricted compared to their AGA peers, indicating dilation of the ventricle (eccentric hypertrophy) $(37,39)$. Another measure that is used to detect ventricle dilation, the left ventricular end diastolic internal diameter, has been found to be greater in infants born growth restricted than in AGA controls $(38,40)$, although this finding has not been consistently reported $(6,41)$. Dilation of the left atrium has been demonstrated by an increased left atrium/aortic root ratio in comparison to AGA controls (26). Cardiac changes in IUGR are thus most often described as cardiomyopathy-like, with dilated ventricles and a more globular cardiac shape compared to controls $(10,26,32,34,37-40,42)$.

\section{CARDIAC FUNCTIONAL IMPAIRMENT}

Alterations in cardiac structure and shape can lead to functional impairment of the heart. Many studies have shown cardiac changes in both systolic and diastolic function in growth-restricted fetuses and these cardiac alterations appear to persist postnatally (Table 2).

\section{Global Cardiac Function}

A recent study demonstrated that neonates born growth restricted show greater variability in the duration of cardiac repolarization than controls, indicating electrophysiological instability (43). These findings were accompanied by signs of diastolic dysfunction and may thus be related to underlying structural and mechanical changes within the heart (43). Altered cardiac electrical activity may predispose individuals born growth restricted to electrophysiological events, which is especially important to consider when drugs that can prolong repolarization are prescribed. Global cardiac performance can be assessed on echocardiography by the myocardial performance index (MPI), also known as the Tei index. An increase of this index, representing diminished systolic and/ or diastolic function, has been reported in fetuses, with even mild IUGR $(7,44,45)$. The MPI has been shown to progressively increase with fetal deterioration (7) and it appears to have a negative association with perinatal outcome (including 5-min Apgar score, cord $\mathrm{pH}$, and perinatal mortality) $(7,46)$. An increased MPI has also been found in neonates following IUGR $(37,40,43)$ and has even been reported in infants born growth restricted up to 3 mo of age (40), suggesting that cardiac dysfunction, although subclinical, can persists beyond the fetal and neonatal period.

\section{Systolic Function}

Growth-restricted fetuses show reduced peak systolic velocities in the major cardiac outflow tracts $(47,48)$ as well as diminished ejection force (the force by which the left and right ventricles accelerate blood into the aorta and pulmonary artery respectively) (49). These findings may be the result of compromised systolic function (48). They are however more likely to result from increased afterload in relation to high placental resistance, since most growth-restricted fetuses are capable of maintaining their cardiac output $(7,48,50)$ and the majority of studies also report normal postnatal systolic function (10,36$41,51)$. Fractional shortening and ejection fraction, both measurements that give an indication of left ventricular pump function, have been found to be similar in growth-restricted and AGA neonates and infants (10,36-41). In most studies, cardiac output of neonates and infants born growth restricted has also been found comparable to controls $(36-38,40,51)$. Moreover, increased stroke volume and cardiac output have been reported in neonates born growth restricted during the first few days of life, which may represent a compensatory mechanism to intrauterine hypoxia $(37,38,52)$. Nevertheless, prolonged exposure to increased afterload and cardiac remodeling may eventually result in systolic dysfunction. A reduction in stroke volume in neonates born growth restricted has been reported in a few studies $(26,37,51)$, although a compensatory increase in heart rate usually maintains cardiac output $(37,51)$. In one study, however, the reduction in stroke volume was not compensated for by an increase in heart rate, resulting in a lower cardiac output in growth restricted compared to AGA term neonates (26). Within this study, compromised systolic function further presented as a reduction in fractional shortening (26). A reduction in fractional shortening and a decrease in stroke volume may not only relate to impaired systolic function, but may also be related to diastolic dysfunction, as suggested by an increase in isovolumetric relaxation time in the study by Seghal et al. (26). Impairment of left ventricular relaxation compromises ventricular filling resulting in reduced end-diastolic volume and thus decreased stroke volume (53). This phenomenon is exacerbated when heart rate increases. Thus, a higher heart rate would not compensate for a decreased stroke volume under these circumstances, and may even further compromise systolic cardiac function.

\section{Diastolic Dysfunction}

As mentioned previously, increased isovolumetric relaxation time-which represents poor myocardial relaxation-suggests diastolic functional impairment following IUGR $(10,26,37)$. Diastolic function can also be assessed by the E/A ratio, which represents the ratio between passive diastolic ventricular filling and additional active filling during atrial contraction (E- and A-wave on Doppler signal). Contrasting results for the E/A ratio have been reported in growth-restricted fetuses, neonates, and infants. Some studies have shown a lowered E/A ratio compared to AGA controls $(37,54)$, suggesting increased stiffness of the ventricular walls and delayed relaxation. However, others have found similar $(10,41)$ or increased $(26,40)$ ratios. In adults with progressing diastolic dysfunction, a lowered E/A ratio is followed by "pseudo-normalization" and a subsequent increase of the ratio (53). Conflicting results could thus potentially reflect different stages of diastolic dysfunction.

\section{Biochemical Evidence of Cardiac Deterioration}

Several studies have provided biochemical evidence of myocardial strain. B-type natriuretic peptide (BNP), which is a protein secreted by the heart in response to volume and pressure 


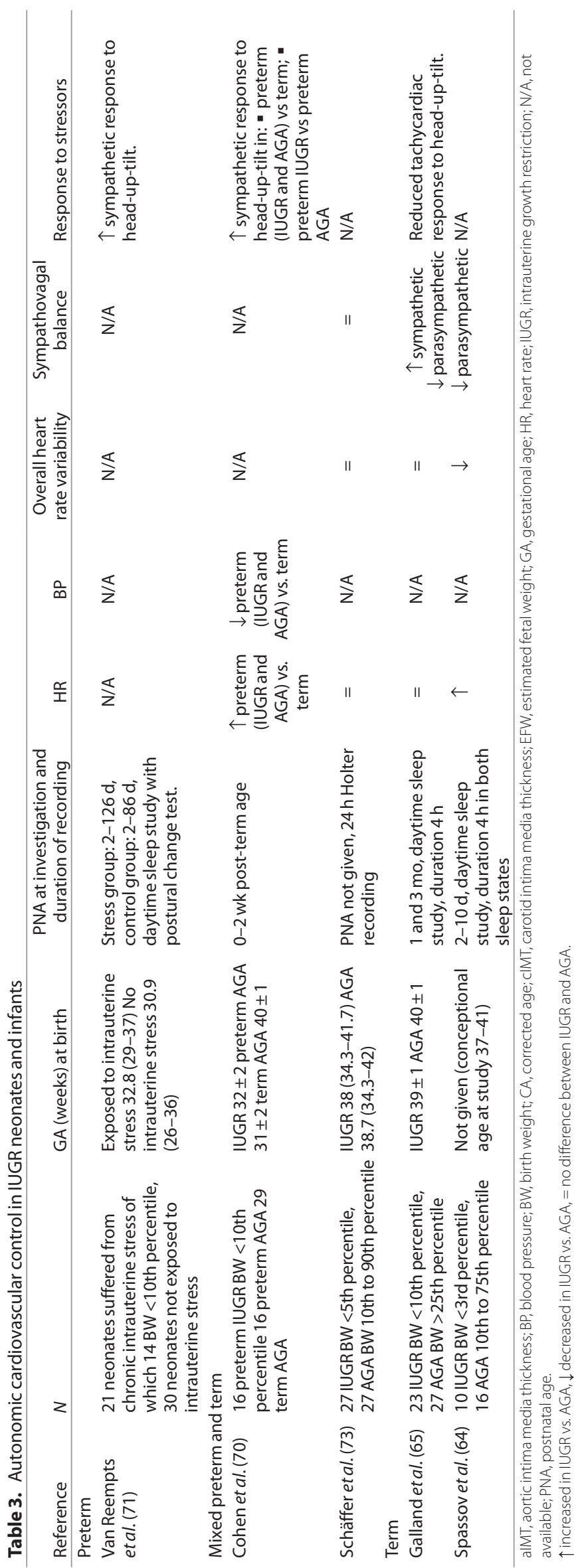

overload, and which is considered indicative for heart failure in adults, was elevated in cord blood and postnatal blood samples from newborns born growth restricted compared to AGA controls $(6,7,50,55)$. These findings provide more evidence to suggest that the fetal heart suffers from the unfavorable intrauterine conditions. In fact, the increase of BNP was significantly correlated with the severity of prenatal Doppler findings $(6,7,50,55)$, suggesting that BNP correlates with deteriorating cardiac condition. BNP was also found to be elevated in growth-restricted neonates on the second day of life (37), although measurements on the fifth postnatal day were no longer different between growth-restricted and AGA neonates (37). Moreover, cardiac troponin $\mathrm{T}$ and $\mathrm{I}$, which are markers for myocardial cell damage, have been detected at birth $(56,57)$ and at $5 \mathrm{~d}$ of age (41) in neonates born growth restricted.

\section{AUTONOMIC CARDIOVASCULAR CONTROL}

Altered cardiovascular function may not only be due to structural changes, but may also be related to adaptations in autonomic cardiovascular control. Modulation of heart rate is regulated by both the sympathetic and parasympathetic autonomic nervous system and neurocardiac function and sympathovagal balance can be investigated by the means of heart rate variability (HRV) analysis (58).

\section{HRV In Growth-Restricted Fetuses and Infants}

Fetal HRV can be monitored by means of cardiotocography and these recordings are taken into consideration when deciding upon obstetric management. A decline in fetal HRV is thought to indicate fetal compromise. Several studies have shown reduced HRV in growth-restricted fetuses compared to AGA peers, indicating that these fetuses are compromised by the unfavorable intrauterine environment (59-62). Moreover, lowered HRV has been clearly associated with fetal acidemia and hypoxia (63). Postnatally, infants born growth restricted may continue to display lowered HRV compared to their AGA peers throughout the first days (64) and even months (65) of life, indicating altered development of cardiovascular control.

\section{Sympathovagal Balance in Growth-Restricted Fetuses and Infants}

Information regarding the contribution of the sympathetic and parasympathetic nerve system in cardiovascular control can be derived from HRV analysis (58). Although controversy regarding this subject exists, low-frequency alterations in heart rate are generally accepted to be influenced by both branches of the autonomic nerve system, whereas high-frequency changes in heart rate represent the fast acting parasympathetic branch only (58). Moreover, the ratio between low-frequency and high-frequency HRV may represent sympathovagal balance. Growth-restricted fetuses were found to have reduced lowfrequency/high-frequency ratio, which could be caused by increased parasympathetic activity as part of an energy preservation strategy when exposed to chronic oxygen and nutrient deprivation $(60,66)$. In support of this, growth-restricted fetuses display less movements (67) and spend more time in 
a quiet behavioral state (68) in which parasympathetic activity prevails (69). In contrast to the results found in growthrestricted fetuses, a relative increase in sympathetic activity has been reported in growth-restricted term born infants up to 3 mo of age $(65,70,71)$. Sympathovagal imbalance, with a predominance of sympathetic activity, is strongly related to hypertension and other risk factors for cardiovascular disease (72) and these findings may thus help explain the increased risk of cardiovascular disease in the IUGR population. Nevertheless, as shown in Table 3, not all studies report differences in HRV and sympathovagal balance between growth-restricted and control subjects (73). This may be due to the heterogeneous populations studied and diversity of methodology employed.

\section{BLOOD PRESSURE FOLLOWING IUGR}

Increased arterial stiffness and sympathetic overactivity may influence blood pressure. It is not surprising that several studies have reported increased blood pressures in neonates $(26,32,37)$, infants $(10,29)$, children, $(30,42)$ and adults (74) born following IUGR. Nevertheless, there are also many reports which do not show an inverse relationship between birth weight and blood pressure at various ages (75). These conflicting results demonstrate that the relationship between fetal growth and blood pressure is complex (75). Factors such as postnatal growth have been shown to greatly influence this relationship (76). Moreover, methodological difficulties and inconsistencies have most likely contributed to the conflicting results reported.

\section{POSTNATAL GROWTH}

Rate of prenatal growth may not be the only contributing factor to cardiovascular abnormalities following IUGR. Some infants born growth restricted show exaggerated postnatal growth, as expressed by crossing growth percentiles during infancy, so called "catch-up growth". It is now believed that these individuals in particular are at increased risk of developing cardiovascular disease. In fact, one of the first cohort studies linking low birthweight to cardiovascular disease showed that girls with low birth weight but highest weight at $1 \mathrm{y}$ of age were at particular risk of coronary heart disease in adult life (77). Other studies have confirmed that the rate of postnatal growth (rather than birth weight alone) contributes to cardiovascular risk factors (78). The thrifty phenotype hypothesis proposes that intrauterine nutrient deprivation leads to metabolic and hormonal adaptations promoting energy conservation in the growth-restricted fetus (79). These include a level of insulin-resistance to ensure adequate glucose supply to the brain at the expense of other organs and also altered adipose tissue metabolism (79). These permanent alterations become detrimental when the individual is exposed to a relative overabundance of nutrients in the postnatal period, predisposing to the metabolic syndrome and type 2 diabetes mellitus, adding to the cardiovascular risk (79). In support of this hypothesis, in a rat model of IUGR, cardiac interstitial fibrosis was not only greater in growth resticted compared to AGA rats, but greatest in those growth restricted exposed to hyperglycemia, demonstrating a synergistic effect of IUGR and metabolic derangement (80).

\section{CONFLICTING FINDINGS}

Although many studies demonstrate cardiovascular abnormalities following IUGR, this review also highlights that many conflicting findings have been reported within this field of research. Conflicting results may be explained by diversity of methodology and heterogeneity within and between study populations (as shown in Tables 1, 2, and 3). Firstly, it is important to differentiate between studies conducted within preterm and term born growth-restricted infants, as prematurity in itself has been shown to affect cardiovascular control and function (58). Nevertheless, even within these distinct populations, contrasting results have been reported regarding cardiac function following IUGR (Table 2). Many different definitions of IUGR have been used within the current literature, as to date no uniform definition of IUGR is in place. This may have also contributed to discrepancies found. Furthermore, the current literature does not differentiate between the underlying causes of IUGR. The etiology of uteroplacental insufficiency is extensive, including smoking, essential hypertension, preeclampsia, and diabetes mellitus (1). The cause of uteroplacental insufficiency, timing of onset, and severity of disease influence fetoplacental hemodynamics, most likely resulting in different cardiovascular phenotypes. It is of great importance that future research takes these factors into account.

\section{SURVEILLANCE AND INTERVENTION}

As discussed above, many studies have demonstrated a broad range of (subclinical) cardiovascular abnormalities in growthrestricted fetuses and neonates, which appear to contribute to the increased cardiovascular risk in adulthood. As discussed previously, however, it remains difficult to correctly diagnose IUGR. Diversity of methodology and heterogeneity within and between study populations have led to conflicting results in the current literature, limiting our ability to correctly identify those fetuses at increased risk of compromised cardiovascular outcome. Moreover, due to the paucity of longitudinal studies investigating cardiovascular development and function throughout infancy, we currently have no understanding of how these cardiovascular abnormalities evolve over time and how they may progress into clinical cardiovascular disease. The scarcity of information regarding these topics limits our opportunities to establish adequate follow-up and interventions.

\section{Identifying Those at Risk: Could Fetal Responses to Antenatal Corticosteroids be Helpful?}

In early onset IUGR, severity of prenatal Doppler findings might allow us to identify those fetuses who are most compromised. A study by Robertson et al. (81) has suggested that the pattern of blood flow changes in the umbilical artery following corticosteroid administration, given prior to preterm birth in order to promote lung maturation, predicts neonatal outcome. In most pregnancies, a transient return of end-diastolic flow 
was observed following antenatal corticosteroid administration (81). In one third of their population, however, absent end-diastolic flow persisted, and neonates from this group showed worse perinatal outcomes (81). Although the physiological mechanisms underlying these changes are not fully understood, persistence of absent or reversed end-diastolic flow in the umbilical artery following corticosteroid administration may represent pregnancies with more severe placental insufficiency, thus putting the fetus at a higher perinatal, and potentially cardiovascular, risk.

\section{Prenatal Intervention}

Placental insufficiency leading to chronic fetal hypoxia and increased oxidative stress have been proposed as the likely underlying pathophysiologic mechanisms of cardiovascular programming related to IUGR (82). Much research has been devoted into antenatal therapies to improve placental blood flow, e.g., sildenafil (83), or to reduce oxidative stress by the use of antioxidants, e.g., melatonin (84). These therapies may offer potential new treatment strategies to ameliorate the negative effects of chronic fetal hypoxia on the developing cardiovascular system.

\section{Postnatal Follow-up and Intervention}

Few studies have investigated cardiovascular structure and function throughout infancy. The available studies indicate that increased arterial and ventricular wall thickness and cardiac dilatation persist beyond the neonatal period $(10,36,40,41)$. Moreover, autonomic cardiovascular control also appears to be permanently altered following IUGR (65). Nevertheless, an improvement of cardiovascular function (as investigated by the MPI and E/A ratio) has been reported despite persistent structural alterations $(10,40)$. This is in contrast to results obtained from studies in older children, which demonstrated subclinical cardiovascular dysfunction at various ages beyond the first year of life $(30,42)$. From these findings, we speculate that, although underlying structural abnormalities and alterations in cardiovascular control persist, infants born growth restricted may initially be capable of restoring full cardiovascular function. We hypothesize that during development and under the influence of other risk factors (such as excessive catch-up growth or exposure to external risk factors), cardiovascular function may again become compromised and progression into chronic cardiovascular disease may occur. We believe that infancy and early childhood may thus create a window of opportunity for interventions preventing progression to chronic disease. Monitoring postnatal growth to prevent excessive weight gain could be part of this strategy. Recent studies have indicated that supplementation with $\omega-3$ fatty acid during infancy and early childhood can prevent excess arterial wall thickening (85) and reduce blood pressure (86) in those born growth restricted. Further research is necessary to investigate how cardiovascular abnormalities following IUGR progress throughout early life and to determine how preventive lifestyle interventions may avoid progression into chronic cardiovascular disease.

\section{CONCLUSIONS}

Although conflicting findings have been reported, the majority of the available literature suggests a negative effect of IUGR on the developing cardiovascular system. It is important to note that most cardiovascular alterations are subclinical and have not consistently been reported to translate into cardiovascular disease. It thus also remains unclear, which IUGR subgroups are at greatest risk of developing cardiovascular sequelae in later life. Moreover, due to the paucity of longitudinal studies investigating cardiovascular function, we currently have very little understanding of how these cardiovascular alterations related to IUGR develop throughout early life and how they may progress into chronic disease. Longitudinal studies, using a uniform definition of IUGR and taking into account the different causes of IUGR are required to gain insight in possible opportunities for early intervention to improve life-long health outcomes for individuals born IUGR.

\section{STATEMENT OF FINANCIAL SUPPORT}

This work is supported by project grant funding from the National Health and Medical Research Council (NHMRC) of Australia (Project No. 1045559) and by the Victorian Government's Operational Infrastructure Support Program. F.Y.W. is supported by a NHMRC Career Development Fellowship (1084254). R.S.C.H. is supported by a NHMRC Senior Research Fellowship (606411); a scholarship was provided to E.C. by SIDS and Kids Australia.

Disclosure: The authors have no conflicts of interest relevant to this article to disclose.

\section{REFERENCES}

1. Cox P, Marton T. Pathological assessment of intrauterine growth restriction. Best Pract Res Clin Obstet Gynaecol 2009;23:751-64.

2. Barker DJ, Winter PD, Osmond C, Margetts B, Simmonds SJ. Weight in infancy and death from ischaemic heart disease. Lancet 1989;2:577-80.

3. World Health Organization. Global Status Report on Noncommunicable Diseases, 2010. http://whqlibdoc.who.int/publications/2011/ 9789240686458_eng.pdf

4. Vayssière C, Sentilhes L, Ego A, et al. Fetal growth restriction and intrauterine growth restriction: guidelines for clinical practice from the French College of Gynaecologists and Obstetricians. Eur J Obstet Gynecol Reprod Biol 2015;193:10-8.

5. Gardosi J. Intrauterine growth restriction: new standards for assessing adverse outcome. Best Pract Res Clin Obstet Gynaecol 2009;23:741-9.

6. Vijlbrief DC, van Bel F, Molenschot MC, et al. Early detection of prenatal cardiocirculatory compromise in small for gestational age infants. Neonatology 2014;105:256-62.

7. Crispi F, Hernandez-Andrade E, Pelsers MM, et al. Cardiac dysfunction and cell damage across clinical stages of severity in growth-restricted fetuses. Am J Obstet Gynecol 2008;199:254.e1-8.

8. Pérez-Cruz M, Cruz-Lemini M, Fernández MT, et al. Fetal cardiac function in late-onset intrauterine growth restriction vs small-for-gestational age, as defined by estimated fetal weight, cerebroplacental ratio and uterine artery Doppler. Ultrasound Obstet Gynecol 2015;46:465-71.

9. Parra-Saavedra M, Crovetto F, Triunfo S, et al. Placental findings in lateonset SGA births without Doppler signs of placental insufficiency. Placenta 2013;34:1136-41.

10. Cruz-Lemini M, Crispi F, Valenzuela-Alcaraz B, et al. Fetal cardiovascular remodelling persists at 6 months of life in infants with intrauterine growth restriction. Ultrasound Obstet Gynecol 2015. Epub ahead of print DOI 10.1002/uog.15767.

11. Baschat AA, Harman CR. Antenatal assessment of the growth restricted fetus. Curr Opin Obstet Gynecol 2001;13:161-8.

12. Turan OM, Turan S, Gungor S, et al. Progression of Doppler abnormalities in intrauterine growth restriction. Ultrasound Obstet Gynecol 2008;32:160-7. 


\section{Cardiovascular function in IUGR infants}

13. Spinillo A, Gardella B, Bariselli S, Alfei A, Silini EM, Bello BD. Cerebroplacental Doppler ratio and placental histopathological features in pregnancies complicated by fetal growth restriction. J Perinat Med 2014;42:321-8.

14. Mari G, Hanif F, Kruger M, Cosmi E, Santolaya-Forgas J, Treadwell MC. Middle cerebral artery peak systolic velocity: a new Doppler parameter in the assessment of growth-restricted fetuses. Ultrasound Obstet Gynecol 2007;29:310-6.

15. Brantberg A, Sonesson SE. Central arterial hemodynamics in small-forgestational-age fetuses before and during maternal hyperoxygenation: a Doppler velocimetric study with particular attention to the aortic isthmus. Ultrasound Obstet Gynecol 1999;14:237-43.

16. Oros D, Figueras F, Cruz-Martinez R, Meler E, Munmany M, Gratacos E. Longitudinal changes in uterine, umbilical and fetal cerebral Doppler indices in late-onset small-for-gestational age fetuses. Ultrasound Obstet Gynecol 2011;37:191-5.

17. Iruretagoyena JI, Gonzalez-Tendero A, Garcia-Canadilla P, et al. Cardiac dysfunction is associated with altered sarcomere ultrastructure in intrauterine growth restriction. Am J Obstet Gynecol 2014;210:550.e1-7.

18. Norman M. Low birth weight and the developing vascular tree: a systematic review. Acta Paediatr 2008;97:1165-72.

19. Humphrey JD. Mechanisms of arterial remodeling in hypertension: coupled roles of wall shear and intramural stress. Hypertension 2008;52: 195-200.

20. Thompson JA, Richardson BS, Gagnon R, Regnault TR. Chronic intrauterine hypoxia interferes with aortic development in the late gestation ovine fetus. J Physiol 2011;589(Pt 13):3319-32.

21. Cosmi E, Visentin S, Fanelli T, Mautone AJ, Zanardo V. Aortic intima media thickness in fetuses and children with intrauterine growth restriction. Obstet Gynecol 2009;114:1109-14.

22. Skilton MR, Evans N, Griffiths KA, Harmer JA, Celermajer DS. Aortic wall thickness in newborns with intrauterine growth restriction. Lancet 2005;365:1484-6.

23. Lo Vasco VR, Salmaso R, Zanardo V, et al. Fetal aorta wall inflammation in ultrasound-detected aortic intima/media thickness and growth retardation. J Reprod Immunol 2011;91:103-7.

24. Koklu E, Kurtoglu S, Akcakus M, et al. Increased aortic intima-media thickness is related to lipid profile in newborns with intrauterine growth restriction. Horm Res 2006;65:269-75.

25. Koklu E, Ozturk MA, Kurtoglu S, Akcakus M, Yikilmaz A, Gunes T. Aortic intima-media thickness, serum IGF-I, IGFBP-3, and leptin levels in intrauterine growth-restricted newborns of healthy mothers. Pediatr Res 2007;62:704-9.

26. Sehgal A, Doctor T, Menahem S. Cardiac function and arterial biophysical properties in small for gestational age infants: postnatal manifestations of fetal programming. J Pediatr 2013;163:1296-300.

27. Iwashima S, Ishikawa T, Akira O, Itou H. Association of abdominal aortic wall thickness in the newborn with maternal factors. Am J Perinatol 2012;29:441-8.

28. Stergiotou I, Crispi F, Valenzuela-Alcaraz B, Cruz-Lemini M, Bijnens B, Gratacos E. Aortic and carotid intima-media thickness in term small-forgestational-age newborns and relationship with prenatal signs of severity. Ultrasound Obstet Gynecol 2014;43:625-31.

29. Cruz-Lemini M, Crispi F, Valenzuela-Alcaraz B, et al. A fetal cardiovascular score to predict infant hypertension and arterial remodeling in intrauterine growth restriction. Am J Obstet Gynecol 2014;210:552.e1-552.e22.

30. Zanardo V, Fanelli T, Weiner G, et al. Intrauterine growth restriction is associated with persistent aortic wall thickening and glomerular proteinuria during infancy. Kidney Int 2011;80:119-23.

31. Akira M, Yoshiyuki S. Placental circulation, fetal growth, and stiffness of the abdominal aorta in newborn infants. J Pediatr 2006;148:49-53.

32. Sehgal A, Doctor T, Menahem S. Cardiac function and arterial indices in infants born small for gestational age: analysis by speckle tracking. Acta Paediatr 2014;103:e49-54.

33. Bubb KJ, Cock ML, Black MJ, et al. Intrauterine growth restriction delays cardiomyocyte maturation and alters coronary artery function in the fetal sheep. J Physiol 2007;578(Pt 3):871-81.
34. Tintu A, Rouwet E, Verlohren S, et al. Hypoxia induces dilated cardiomyopathy in the chick embryo: mechanism, intervention, and long-term consequences. PLoS One 2009;4:e5155.

35. Takahashi N, Nishida H, Arai T, Kaneda Y. Abnormal cardiac histology in severe intrauterine growth retardation infants. Acta Paediatr Jpn 1995;37:341-6.

36. Czernik C, Rhode S, Metze B, Bührer C, Schmitz L. Comparison of left ventricular cardiac dimensions between small and appropriate for gestational age preterm infants below 30 weeks of gestation. J Perinat Med 2013;41:219-26.

37. Fouzas S, Karatza AA, Davlouros PA, et al. Neonatal cardiac dysfunction in intrauterine growth restriction. Pediatr Res 2014;75:651-7.

38. Leipälä JA, Boldt T, Turpeinen U, Vuolteenaho O, Fellman V. Cardiac hypertrophy and altered hemodynamic adaptation in growth-restricted preterm infants. Pediatr Res 2003;53:989-93.

39. Cinar B, Sert A, Gokmen Z, Aypar E, Aslan E, Odabas D. Left ventricular dimensions, systolic functions, and mass in term neonates with symmetric and asymmetric intrauterine growth restriction. Cardiol Young 2013:1-7.

40. Altın H, Karaarslan S, Karataş Z, Alp H, Şap F, Baysal T. Evaluation of cardiac functions in term small for gestational age newborns with mild growth retardation: a serial conventional and tissue Doppler imaging echocardiographic study. Early Hum Dev 2012;88:757-64.

41. Gürses D, Seyhan B. Evaluation of cardiac systolic and diastolic functions in small for gestational age babies during the first months of life: a prospective follow-up study. Cardiol Young 2013;23:597-605.

42. Crispi F, Bijnens B, Figueras F, et al. Fetal growth restriction results in remodeled and less efficient hearts in children. Circulation 2010;121: 2427-36.

43. Fouzas S, Karatza AA, Davlouros PA, et al. Heterogeneity of ventricular repolarization in newborns with intrauterine growth restriction. Early Hum Dev 2014;90:857-62.

44. Benavides-Serralde A, Scheier M, Cruz-Martinez R, et al. Changes in central and peripheral circulation in intrauterine growth-restricted fetuses at different stages of umbilical artery flow deterioration: new fetal cardiac and brain parameters. Gynecol Obstet Invest 2011;71:274-80.

45. Cruz-Martinez R, Figueras F, Hernandez-Andrade E, Oros D, Gratacos E. Changes in myocardial performance index and aortic isthmus and ductus venosus Doppler in term, small-for-gestational age fetuses with normal umbilical artery pulsatility index. Ultrasound Obstet Gynecol 2011;38:400-5

46. Nassr AA, Youssef AA, Zakherah MS, Ismail AM, Brost BC. Clinical application of fetal left modified myocardial performance index in the evaluation of fetal growth restriction. J Perinat Med 2015;43:749-54.

47. Rizzo G, Arduini D. Fetal cardiac function in intrauterine growth retardation. Am J Obstet Gynecol 1991;165(4 Pt 1):876-82.

48. Verburg BO, Jaddoe VW, Wladimiroff JW, Hofman A, Witteman JC, Steegers EA. Fetal hemodynamic adaptive changes related to intrauterine growth: the Generation R Study. Circulation 2008;117:649-59.

49. Rizzo G, Capponi A, Rinaldo D, Arduini D, Romanini C. Ventricular ejection force in growth-retarded fetuses. Ultrasound Obstet Gynecol 1995;5:247-55.

50. Girsen A, Ala-Kopsala M, Mäkikallio K, Vuolteenaho O, Räsänen J. Cardiovascular hemodynamics and umbilical artery $\mathrm{N}$-terminal peptide of proB-type natriuretic peptide in human fetuses with growth restriction. Ultrasound Obstet Gynecol 2007;29:296-303.

51. Robel-Tillig E, Knüpfer M, Vogtmann C. Cardiac adaptation in small for gestational age neonates after prenatal hemodynamic disturbances. Early Hum Dev 2003;72:123-9.

52. Guajardo CD, Mandelbaum V, Linderkamp O. Cardiac output and cerebral blood flow velocity in small for gestational age infants during the first 5 days after birth. Early Hum Dev 1994;37:187-93.

53. Vitarelli A, Gheorghiade M. Diastolic heart failure: standard Doppler approach and beyond. Am J Cardiol 1998;81(12A):115G-21G.

54. Harada K, Suzuki T, Takahashi Y, et al. Abnormal left ventricular diastolic filling patterns in small-for-gestational-age infants. Early Hum Dev 1998;51:197-204. 
55. Bahlmann F, Krummenauer F, Spahn S, Gallinat R, Kampmann C. Natriuretic peptide levels in intrauterine growth-restricted fetuses with absent and reversed end-diastolic flow of the umbilical artery in relation to ductus venosus flow velocities. J Perinat Med 2011;39:529-37.

56. Mäkikallio K, Vuolteenaho O, Jouppila P, Räsänen J. Association of severe placental insufficiency and systemic venous pressure rise in the fetus with increased neonatal cardiac troponin T levels. Am J Obstet Gynecol 2000;183:726-31.

57. Chaiworapongsa T, Espinoza J, Yoshimatsu J, et al. Subclinical myocardial injury in small-for-gestational-age neonates. J Matern Fetal Neonatal Med 2002;11:385-90.

58. Yiallourou SR, Wallace EM, Miller SL, Horne RS. Effects of intrauterine growth restriction on sleep and the cardiovascular system: The use of melatonin as a potential therapy? Sleep Med Rev 2016;26:64-73.

59. Nijhuis IJ, ten Hof J, Mulder EJ, et al. Fetal heart rate in relation to its variation in normal and growth retarded fetuses. Eur J Obstet Gynecol Reprod Biol 2000;89:27-33.

60. Vinkesteijn AS, Struijk PC, Ursem NT, Hop WC, Wladimiroff JW. Fetal heart rate and umbilical artery flow velocity variability in intrauterine growth restriction: a matched controlled study. Ultrasound Obstet Gynecol 2004;23:461-5.

61. Graatsma EM, Mulder EJ, Vasak B, et al. Average acceleration and deceleration capacity of fetal heart rate in normal pregnancy and in pregnancies complicated by fetal growth restriction. J Matern Fetal Neonatal Med 2012;25:2517-22.

62. Sriram B, Mencer MA, McKelvey S, et al. Differences in the sleep states of IUGR and low-risk fetuses: An MCG study. Early Hum Dev 2013;89: 815-9.

63. Ribbert LS, Snijders RJ, Nicolaides KH, Visser GH. Relation of fetal blood gases and data from computer-assisted analysis of fetal heart rate patterns in small for gestation fetuses. Br J Obstet Gynaecol 1991;98:820-3.

64. Spassov L, Curzi-Dascalova L, Clairambault J, et al. Heart rate and heart rate variability during sleep in small-for-gestational age newborns. Pediatr Res 1994;35(4 Pt 1):500-5.

65. Galland BC, Taylor BJ, Bolton DP, Sayers RM. Heart rate variability and cardiac reflexes in small for gestational age infants. J Appl Physiol (1985) 2006;100:933-9.

66. Gonçalves H, Bernardes J, Ayres-de-Campos D. Gender-specific heart rate dynamics in severe intrauterine growth-restricted fetuses. Early Hum Dev 2013;89:431-7.

67. Pagani G, D’Antonio F, Khalil A, et al. Association between reduced fetal movements at term and abnormal uterine artery Doppler indices. Ultrasound Obstet Gynecol 2014;43:548-52.

68. Gazzolo D, Visser GH, Santi F, et al. Behavioural development and Doppler velocimetry in relation to perinatal outcome in small for dates fetuses. Early Hum Dev 1995;43:185-95.

69. van Laar JO, Peters CH, Vullings R, Houterman S, Oei SG. Power spectrum analysis of fetal heart rate variability at near term and post term gestation during active sleep and quiet sleep. Early Hum Dev 2009;85:795-8.
70. Cohen G, Vella S, Jeffery H, Lagercrantz H, Katz-Salamon M. Cardiovascular stress hyperreactivity in babies of smokers and in babies born preterm. Circulation 2008;118:1848-53.

71. Van Reempts PJ, Wouters A, De Cock W, Van Acker KJ. Stress responses to tilting and odor stimulus in preterm neonates after intrauterine conditions associated with chronic stress. Physiol Behav 1997;61:419-24.

72. Pal GK, Pal P, Nanda N, Amudharaj D, Adithan C. Cardiovascular dysfunctions and sympathovagal imbalance in hypertension and prehypertension: physiological perspectives. Future Cardiol 2013;9:53-69.

73. Schäffer L, Burkhardt T, Müller-Vizentini D, et al. Cardiac autonomic balance in small-for-gestational-age neonates. Am J Physiol Heart Circ Physiol 2008;294:H884-90.

74. Spence D, Stewart MC, Alderdice FA, Patterson CC, Halliday HL. Intrauterine growth restriction and increased risk of hypertension in adult life: a follow-up study of 50-year-olds. Public Health 2012;126:561-5.

75. Huxley R, Neil A, Collins R. Unravelling the fetal origins hypothesis: is there really an inverse association between birthweight and subsequent blood pressure? Lancet 2002;360:659-65.

76. Singhal A, Cole TJ, Fewtrell M, et al. Promotion of faster weight gain in infants born small for gestational age: is there an adverse effect on later blood pressure? Circulation 2007;115:213-20.

77. Osmond C, Barker DJ, Winter PD, Fall CH, Simmonds SJ. Early growth and death from cardiovascular disease in women. BMJ 1993;307:1519-24.

78. Hindmarsh PC, Bryan S, Geary MP, Cole TJ. Effects of current size, postnatal growth, and birth size on blood pressure in early childhood. Pediatrics 2010;126:e1507-13.

79. Hales CN, Barker DJ. The thrifty phenotype hypothesis. Br Med Bull 2001;60:5-20.

80. Lim K, Lombardo P, Schneider-Kolsky M, Black MJ. Intrauterine growth restriction coupled with hyperglycemia: effects on cardiac structure in adult rats. Pediatr Res 2012;72:344-51.

81. Robertson MC, Murila F, Tong S, Baker LS, Yu VY, Wallace EM. Predicting perinatal outcome through changes in umbilical artery Doppler studies after antenatal corticosteroids in the growth-restricted fetus. Obstet Gynecol 2009;113:636-40.

82. Giussani DA, Niu Y, Herrera EA, et al. Heart disease link to fetal hypoxia and oxidative stress. Adv Exp Med Biol 2014;814:77-87.

83. Satterfield MC, Bazer FW, Spencer TE, Wu G. Sildenafil citrate treatment enhances amino acid availability in the conceptus and fetal growth in an ovine model of intrauterine growth restriction. J Nutr 2010;140:251-8.

84. Miller SL, Wallace EM, Walker DW. Antioxidant therapies: a potential role in perinatal medicine. Neuroendocrinology 2012;96:13-23.

85. Skilton MR, Ayer JG, Harmer JA, et al. Impaired fetal growth and arterial wall thickening: a randomized trial of $\omega-3$ supplementation. Pediatrics 2012;129:e698-703.

86. Skilton MR, Raitakari OT, Celermajer DS. High intake of dietary longchain $\omega-3$ fatty acids is associated with lower blood pressure in children born with low birth weight: NHANES 2003-2008. Hypertension 2013;61:972-6. 